\title{
The 11th Chinese National Conference on X-ray Diffraction and ICDD Workshop
}

The 11th national conference on X-ray diffraction and ICDD workshop was held in Chuangchun, China from July 27 to August 3, 2012 with one day solely devoted to ICDD Workshop in one general session. The conference and the workshop were jointly organized by the Commission on Powder Diffraction, Chinese Crystallographic Society, the Commission on X-ray Diffraction, Chinese Society of Physics, National Natural Science Foundation of China (NSFC), International Centre for Diffraction Data (ICDD), and Beijing Ceramic Society. The local organizers were Jilin University and Jilin Physics Society. Over 260 participants from universities, institutions, and industrials, and facility vendors attended the conference and the workshop.

During the conference, 15 plenary talks and 60 session talks were presented, covering the fundamental research, experimental techniques, structure determination, and applications in various fields. Dr Ting Huang, Editor-in-Chief, was present in the conference and workshop. He again suggested to me to choose some papers to be published in the Powder Diffraction journal, showing the recent advances on the research and applications of X-ray diffraction and related fields done by the Chinese X-ray diffraction community. I was glad to do so. As a result, ten papers are included in this issue through the special efforts of Dr Ting Huang, Nicole Boris, contributors, and many others. I must say that these selected papers are neither meant to be at the highest scientific level, nor to cover all aspects in the field of X-ray diffraction in China. Instead, they are some typical research done recently by the Chinese community. I hope that readers of the Powder Diffraction journal can find these papers enjoyable and useful.

Diffraction technique is becoming more and more popular in both academic researches and industrial applications with a trend of increasing use of neutron and synchrotron diffractions in China. I hope that I have opportunities to bring more research work by the Chinese community to the Powder Diffraction readers in the future.

X.L. Chen Editor for the supplement issue 